mental disease or handicap, or both, are well recognised. Recent surveys undertaken by the Association of British Neurologists have shown that the existing burden of clinical work and responsibility shouldered by clinical neurologists in Britain is such as to demand an urgent increase in the consultant establishment. We can but hope that Achieving a Balance will start this process. The council of the association recently confirmed that neurologists are willing to play an increasing part in managing neurological disability, but this will be possible only when existing clinical pressures are relieved.

The advice which doctors and health authorities have received from innumerable authoritative sources over more than 30 years is unequivocal and clear. We have heard about the Cinderella specialties, and rehabilitation is plainly one. Resources are finite and rapid expansion may be impracticable, but a rapid ascent for this specialty in the priority stakes is clearly justified-and neurologists are prepared to participate fully. And surely all health authorities should urgently re-examine the rehabilitation facilities they now provide and correct the most glaring deficiencies.

\section{SIR JOHN WALTON}

\section{President,}

Association of British Neurologists,

Green College,

Oxford OX2 6HG

1 Gloag D. Needs and opportunities in rehabilitation. BrMed $\mathcal{f}_{1985 ; 290: 43,132,220,301,368,455}$ $542,617,699,768,834,913,981,1059,1135,1201,1333$.

2 British Medical Association. The rehabilization and resettlement of disabled persons. London: BMA 1954.

3 Department of Health and Social Security, Central Health Services Council. Rehabilitation London: HMSO, 1972.

4 Scottish Home and Health Department, Scottish Health Services Council. Medical rehabilitation. Edinburgh: HMSO, 1972

5 Royal College of Physicians of London. Physical disability in 1986 and beyond. $\mathcal{f} R$ Coll Physician Lond 1986;20:160-94.

\title{
Smallpox ten years gone: what next?
}

Ten years ago this week in Merka, Somalia, the last naturally occurring case of smallpox in the world was reported. This was the first and only time that a positive attempt to eradicate an infection had succeeded. What are the prospects for eradicating other diseases?

Eradication is "the extinction of the pathogen that causes the infectious disease in question." In elimination the disease disappears but the causative agent remains. The characteristics of an infection that may make it eradicable are its limitation to humans, an easily recognisable illness with no subclinical or latent infection, no long term carriers, lifelong immunity with visible evidence of immunity, low to moderate infectivity, a medium to long incubation period, ${ }^{2}$ and, of course, the availability of an effective tool for interrupting transmission. Smallpox had all these characteristics.

The six target diseases of the World Health Organisation's expanded programme on immunisation are measles, pertussis, neonatal tetanus, polio, tuberculosis, and diphtheria. ${ }^{3}$ Many of the factors necessary for elimination are present for each of these diseases-but some are not. Measles immunity is not easily recognisable, and the infection is so highly communicable that a vaccine efficacy rate of about $95 \%$ is probably not high enough even to eliminate, much less eradicate, the disease. ${ }^{4}$ An outbreak of measles recently occurred in a secondary school in the United States, although more than $99 \%$ of the students were vaccinated and $95 \%$ had serological immunity. ${ }^{5}$ Pertussis is also highly infectious, immunity is not recognisable, and the vaccine is almost certainly not effective enough and in any case probably does not prevent carriage of the organism. As Clostridium tetani is ubiquitous tetanus is not eradicable. Neonatal tetanus could theoretically be eliminated in the Third World if $100 \%$ of pregnant women were vaccinated, but in practice combining immunisation and health education should prove more effective.

Most infection with poliovirus is subclinical, and immunity is clinically unrecognisable. But countries that are efficient at giving vaccines have proved remarkably successful not only in practically eliminating the disease but also in virtually eradicating the organism; the Pan American Health Organ- isation aims at eradicating polio from the Americas by $1990 .{ }^{6}$ Nevertheless, the widespread use of the live vaccine has led to the circulating wild virus being replaced by the vaccine virus, ${ }^{7}$ which has some neurological side effects of its own. Tuberculosis is clearly not eradicable at present, and, although little of the decreasing incidence and severity of the disease of the last century can be attributed to medical planning, much can still be done to further reduce its incidence.

Diphtheria has many features that suggest that it cannot easily be eradicated, especially as in theory the vaccine should not affect the carrier state. Nevertheless, with a national immunisation rate in Britain of $84 \%$ not only are cases of diphtheria rare but so also are isolations of toxigenic strains. Such cases and strains are occasionally reported, however, and serological studies and localised outbreaks in countries with high immunisation rates ${ }^{89}$ suggest that we cannot be complacent.

Prospects for eradicating congenital rubella syndrome are more encouraging. Cases reported each year in the United States have declined steadily: only two cases were reported in 1984 and $1985 . .^{10}$ Although the syndrome is notoriously undernotified and underdiagnosed, reduction has been achieved by universal immunisation augmented by selective immunisation of adult women of childbearing age; recently announced changes in British policy are intended to eliminate rubella and the congenital rubella syndrome although prospects for eradicating the virus are remote.

The case for eliminating mumps on grounds of cost benefit is not strong, ${ }^{11}$ but it strengthens when mumps vaccine is given with measles and rubella. The prospects for elimination or eradication are probably similar to those for rubella; a vaccine coverage rate of $85 \%$ at the age of 2 years is said to be adequate. ${ }^{12}$ With all these diseases there are epidemiological side effects of mass immunisation, ${ }^{4}$ which are mainly those of altering the age distribution of the disease. ${ }^{513}$

Clearly we cannot be wildly optimistic about eradicating many infections with vaccines in the near future, but strategies other than immunisation are available. The universal provision of safe drinking water will eradicate diseases transmitted solely by this route-for example, 
guinea worm, which the World Health Organisation has already announced its intention of eradicating. This simple, single, safe public health measure will also considerably reduce the burden of several other diseases, including typhoid, cholera, and epidemic non-A hepatitis.

\section{NORMAN D NOAH} NORMAN T BEGG

Consultant Epidemiologists,

Public Health Laboratory Service,

Communicable Disease Surveillance Centre,

London NW9 5EQ

1 Cockburn TA. Eradication of infectious diseases. Science 1961;133:1050.

2 Hopkins DR, Koplan JP, Hinman AR, Lane JM. The case for global measles eradication. Lance 1982;ii:1396-8.

3 Henderson RH. The expanded programme on immunization of the World Health Organization. Rev Infect Dis 1984:6(suppl 2):475-9.

4 Noah ND. The elimination of measles. In: Silman AJ, Allwright SPA, eds. Disease elimination or reduction? Oxford: Oxford Medical Publications (in press).

5 Gustafson TL, Lievens AW, Brunell PA, Moellenber RG, Buttery MG, Sehulster LM. Measles outbreak in a fully immunized secondary school population. N Engl F Med 1987;316:771-4.

6 Pan American Health Organization. Goal for 1990; polio eradication in the Americas. EPI Newsletter 1985;7(June): 1-2.

7 Cossart YE. Evolution of poliovirus since introduction of attenuated vaccine. $\mathrm{Br}$ Med $\mathfrak{J}$ 1977;i:1621-3.

8 Björkholm B, Böttiger M, Christenson B, Hagberg L. Antitoxin antibody levels and the outcome of illness during an outbreak of diphtheria among alcoholics. Scand f Infect Dis 1986;18:235-9.

9 Christenson B, Böttiger M. Serological immunity to diphtheria in Sweden in 1987 and 1984. Scand 7 Infect Dis 1986;18:227-33.

10 Centers for Disease Control. Rubella and congenital rubella syndrome-United States, 1985-6. Morbidity and Mortality Weekly Report 1986;35:129-34.

11 Noah ND. Elimination of mumps. In: Silman AJ, Allwright SPA, eds. Disease elimination or reduction? Oxford: Oxford Medical Publications (in press).

12 Anderson RM, Crombie JA, Grenfell BT. The epidemiology of mumps in the UK: a preliminary study of virus transmission, immunity and the potential impact of immunization. Epidem In 1987;99:65-84.

13 Centers for Disease Control. Mumps outbreaks on university campuses-Illinois, Wisconsin South Dakota. Morbidity and Mortality Weekly Report 1987;36:496-505.

\section{Respiratory care in muscular dystrophy}

Duchenne muscular dystrophy, the commonest neuromuscular disorder in childhood, is relentlessly progressive: most boys can no longer walk by the age of 12 and they die in their teens or early 20s. Adolescence is characterised by a steady fall in the vital capacity, resulting from increasing muscle weakness and scoliosis. At first the tidal volume is maintained, but eventually it also falls. A prospective study showed that almost three quarters of patients die from hypercapnoea due to chronic respiratory insufficiency. ${ }^{1}$ When the vital capacity fell below $700 \mathrm{ml}$ the risk of death was high and clinical signs of hypoventilation appeared.

Clearly there are considerable problems in respiratory management, and in a recent review Smith and his colleagues emphasised that an important component is to try to control the scoliotic contribution to the falling vital capacity. ${ }^{2}$ Since scoliosis develops because the child can no longer walk its onset can be delayed by prolonging ambulation with lightweight knee-ankle-foot orthoses. ${ }^{3}$ Once the child is permanently in a wheelchair wearing a spinal brace may prevent scoliosis but only if the curvature is minimal. If the scoliosis is $30^{\circ}$ or more, and the boy is still growing, internal fixation of the spine is usually necessary, and the Luque operation has revolutionised this approach. ${ }^{4}$

Obesity, which is frequent in Duchenne muscular dystrophy, may also restrict breathing, and prophylactic dietary restriction is important. ${ }^{5}$ Respiratory muscle training and intermittent positive pressure respiration may help to maintain the vital capacity, though these methods require more systematic evaluation. ${ }^{2}$

Ventilatory failure occurs late in the condition, and only when the boy has become confined to a chair. This is in contrast to the less progressive neuromuscular disorders, such as the congenital myopathies, where patients may have severe hypoventilation yet still be ambulant. In congenital myopathy the most severe hypoventilation occurs during sleep, and ventilatory support during the night may correct the chronic hypoxia and hypercapnoea with dramatic clinical improvement. . $^{6-10}$

It is not certain why there is this difference between Duchenne muscular dystrophy and congenital myopathy in the timing of ventilatory failure. It may relate to the greater diaphragmatic weakness in congenital myopathy, as the diaphragm is responsible for the major part of the ventilatory drive during sleep. ${ }^{6}$ Weakness of the diaphragm can be assessed by measuring the transdiaphragmatic pressure with balloon catheters, but few young patients can cooperate with this technique. A simpler but indirect way is to measure the fall in the vital capacity in the supine as compared with the erect posture, a difference of $25 \%$ indicating definite diaphragmatic weakness. Smith and his colleagues found such a fall in a fifth of their boys with Duchenne muscular dystrophy, ${ }^{2}$ and it occurs only in the non-ambulant phase of the disease. ${ }^{11}$ They also found nocturnal hypoventilation in six out of 10 boys with advanced disease, and the more severe cases had apnoea related to rapid eye movement sleep with severe oxygen desaturation.

Ventilatory support, whether to treat or prevent hypoventilation, is the most controversial aspect of respiratory care in Duchenne muscular dystrophy. Some workers have used the rocking bed, ${ }^{12}$ cuirass ventilator, ${ }^{13}$ or positive pressure ventilator with a face mask. ${ }^{14}$ These non-invasive methods may produce a worthwhile relief of symptoms. Ventilation using a tracheostomy is also effective, ${ }^{115}$ but it raises the major ethical dilemma of prolonging life beyond the point at which the boy has incapacitating bulbar weakness. As Smith et al point out, we have few respiratory data to guide us over this contentious topic and no firm agreement about the type of management. ${ }^{2}$ Future work should take into account not only the extension of survival that may be achieved but also the relief of symptoms and quality of life attained.

J Z HECKMATT

Lecturer in Paediatric Neurology,

Department of Paediatrics and

Jerry Lewis Muscle Research Centre,

Royal Postgraduate Medical School,

London W12 0HS

1 Rideau Y, Gatin G, Bach J, Gines G. Prolongation of life in Duchenne's muscular dystrophy. Acta Neurol (Napoli) 1983;38:118-24.

2 Smith PEM, Calverly PMA, Edwards RHT, Evans GA, Campbell EJM. Practical problems in the respiratory care of patients with muscular dystrophy. N Engl f Med 1987;316:1197-204.

3 Heckmatt JZ, Dubowitz V, Hyde SA, Florence J, Gabain AC, Thompson N. Prolongation of walking in Duchenne muscular dystrophy with lightweight orthoses: a review of 57 cases. Deo Med Child Neurol 1985;27:149-54.

4 Luque ER. Segmental spinal instrumentation for correction of scoliosis. Clin Orthop 1982;163: 192-8.

5 Edwards RHT, Round JM, Jackson MJ, Griffiths RD, Lilburn MF. Weight reduction in boys with muscular dystrophy. Dev Med Child Neurol 1984;26:384-90.

6 Newson Davis J, Goldman M, Loh L, Casson M. Diaphragm function and alveolar hypoventilation. Qf Med 1976;45:87-100.

7 Riley DJ, Santiago TV, Danielle RP, Schall RP, Edelman NH. Blunted respiratory drive in congenital myopathy. Am $\mathcal{J}$ Med 1977;63:459-65.

8 O'Leary J, King R, Leblanc M, Moss R, Leibhaber M, Lewiston N. Cuirass ventilation in childhood neuromuscular disease. J Pediatra 1979;94:419-21.

9 Maayan Ch, Springer C, Armon Y, Bar-Yishay E, Shapira Y, Godfrey S. Nemaline myopathy as a cause of sleep hypoventilation. Pediatrics 1986;77:390-S.

10 Trend P St J, Wiles CM, Spencer GT, Morgan-Hughes JA, Lake BD, Patrick AD. Acid maltase deficiency in adults. Brain 1985;108:845-60.

11 Noble-Jamieson CM, Heckmatt JZ, Dubowitz V, Silverman M. The effect of posture and spin bracing on respiratory function in neuromuscular disease. Arch Dis Child 1986;61:178-81. 